\title{
Editorial
}

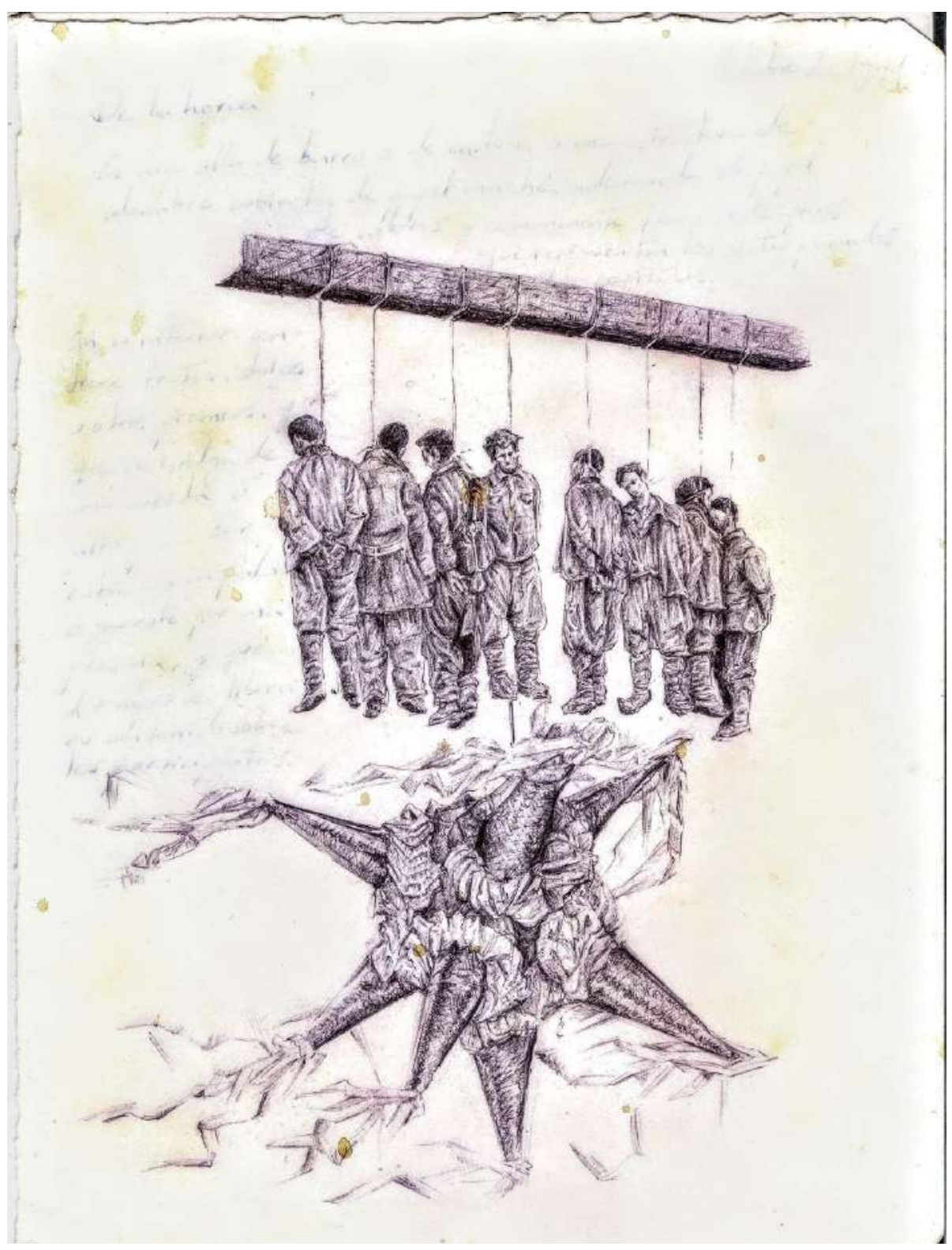

Sebastián Zea Quintero

Sin título

De la serie Del juego y el hombre Lápiz sobre papel 2017

Medellín 


\section{Contribución del capital social a los desafíos sociales y económicos que plantea el Covid-19}

La nueva normalidad que ha impuesto el Covid-19 a todas las sociedades, sin importar su grado de desarrollo, se presenta como un reto sin igual en los tiempos recientes. Los desafíos económicos y sociales que ha generado la pandemia destacan por su relevancia e impacto en el corto y largo plazo en la vida de las personas. Para el inicio de junio de 2020 se cuentan en el mundo cerca de 6 millones de personas infectados y más de 350 mil fallecidos por cuenta del Covid-19. En Colombia las cifras superan los 33 mil contagios y 1100 personas fallecidas.

Lo que significa que, a un poco más de seis meses de haberse confirmado los primeros casos de Covid-19, la incertidumbre y el pánico colectivo no han podido disiparse. Los gobiernos y sociedades no paran de aprender de la nueva enfermedad y ponen a prueba soluciones de todo tipo, buscando dar una respuesta a las tensiones entre cuidar la vida de las personas - a través de medidas estrictas de confinamiento de la poblacióny mitigar los impactos en la actividad económica, que de persistir en el mediano y largo plazo, amenazan con generar caídas significativas en el PIB mundial y afectar gravemente los indicadores socioeconómicos de empleo e ingreso de los hogares.

Particularmente en Colombia, las cifras de ocupación reveladas por el Departamento Administrativo Nacional de Estadísticas (DANE) para el mes de abril de 2020 muestran una tasa de desempleo de 19,8\%, cifra que, comparada con la tasa del mismo periodo del año anterior, muestra un incremento de casi 10\%, cerca de 5,37 millones de nuevos cesantes en Colombia. De allí que se espera que esta coyuntura impacte de manera significativa los avances conseguidos en materia de lucha contra la pobreza en el país en los últimos veinte años (DANE, 2020).

Se destaca el hecho de que las consecuencias del avance del Covid-19 se han sentido con mayor fuerza en las ciudades, territorios que, aunque con mayores recursos y capacidades instaladas, poseen mayor densidad poblacional y dinámicas urbanas que privilegian el contacto estrecho; en 
contraste, las poblaciones rurales han logrado mantener sus dinámicas sociales y económicas con menores impactos negativos, aunque no por ello su situación es menos preocupante. Desde el punto de vista del desempleo, la tasa en las trece principales ciudades y sus áreas metropolitanas es de 23,5\%, en contraposición con $11,7 \%$ de los centros poblados y rurales dispersos (DANE, 2020).

En cuanto a la pobreza, el panorama para Colombia en 2018 — los datos más recientes disponibles-, la línea de pobreza monetaria nacional fue de COL $\$ 257433$, equivalente a un crecimiento de $2,7 \%$ respecto a la línea de 2017 que fue de $\operatorname{COL} \$ 250$ 620, lo cual se tradujo en una incidencia en términos porcentuales de la pobreza extrema en $27 \%$ de la población, manteniendo una tendencia estable desde 2014; en términos de la pobreza multidimensional nacional, esta se situó en 19,6\% (DANE, 2019, mayo 3). Panorama que sin duda cambiará negativamente con la pandemia del Covid-19.

Como es de esperar, gran parte de la solución y los medios para afrontar los desafíos sociales y económicos del Covid-19 están en manos de la institucionalidad, la cual ha respondido con programas que incrementan las trasferencias directas a las personas y a las empresas que, aunque insuficientes frente a la magnitud de las necesidades, van en la dirección correcta. El refuerzo de programas como Colombia Mayor, Familias y Jóvenes en Acción, y la puesta en marcha de los programas de Ingreso Solidario y Devolución del IVA dan cuenta de dichas respuestas.

Además de este importante apoyo estatal, la sociedad civil cuenta con instrumentos para hacerle frente a las consecuencias de Covid-19. Como colectivo, posee el capital social que es un importantísimo activo que bien utilizado puede ser un recurso clave en la coyuntura actual. Cuando la ciudadanía hace uso de valores sociales tan importantes como la amistad, la cooperación, la confianza y la reciprocidad, estan utilizando, precisamente, el capital social. Concepto que alude a los sentimientos de solidaridad, reciprocidad y cooperación que una persona o grupo sienten por otra persona o grupo, y que son retroalimentadas con actitudes de confianza, en las que se incluyen también la empatía, el sentido de obligación y la confianza hacia los otros miembros de la sociedad (Restrepo y Valencia, 2009). Es decir, el capital social, desde el punto de vista económico, es un activo con el que cuentan las personas, los grupos y las comunidades en general para acceder a otros 
capitales de forma coordinada y con ellos a bienes y servicios necesarios para la vida (Putnam, 1993, p. 167). Su importancia radica en la capacidad que tiene para contribuir a que las personas puedan acceder a otros recursos, en especial económicos. Las personas usan este capital para conseguir objetivos, algunos tan sencillos como ayudas para alimentos y otros más complejos como compañía para conversar y así menguar las crisis de ansiedad en medio del aislamiento.

Lo anterior provoca que el capital social pueda ser visto como una herramienta para hacer frente a las situación actual de crisis sanitaria y sus impactos sobre la pobreza, contribuyendo a ampliar los mecanismos de protección para las personas y a crear nuevas oportunidades de desarrollo (James, Schultz y van Olphen, 2001). De allí que desde el inicio del nuevo siglo el Banco Mundial (2001) reconociera cómo el capital social permite a los actores, en su conjunto, movilizar recursos y lograr metas comunes: «sirve de mecanismo de seguro para los pobres que no tienen acceso a las alternativas de mercado. Por tanto, es importante facilitar la formación de nuevas redes cuando las antiguas se están desintegrando» (p. 19).

En investigaciones más recientes sobre la importancia del capital social en la respuesta a la crisis del Covid-19 (Pitas y Ehmer, 2020) se sugiere que comunidades con altos niveles de capital social responden mejor a escenarios de crisis que las comunidades en donde estos niveles son más bajos; asimismo, se recomienda a los entes gubernamentales invertir en la consolidación de redes sociales de apoyo de las comunidades como estrategia de superación de las consecuencias más nefastas del aislamiento, las cuales no se reducen solo a los impactos económicos, sino que tienen efectos significativos en la salud mental de las personas (Rajkumar, 2020). De ahí la importancia del capital social en la actual coyuntura, pues permite alivianar y distribuir las cargas dentro de los grupos sociales que impone el Covid-19. La existencia de redes de apoyo hace posible que familias e individuos en condición de pobreza o en riesgo de caer en ella mitiguen las presiones e impactos sobre sus condiciones básicas de vida, provocando que las comunidades más vulnerables encuentren por mano propia oportunidades y alivios económicos necesarios en medio de la crisis, que sumados a los programas oficiales amplifican la capacidad resiliente de las comunidades.

La propuesta para los hacedores de políticas en momentos de crisis sanitaria es que se trabajen en el diseño de proyectos y programas que le 
apuesten al fortalecimiento del capital social. Se sugieren inversiones tendientes a fomentar la cohesión social, en potenciar las relaciones de confianza, las redes sociales y las organizaciones voluntarias cívicas como instrumentos básicos para la lucha contra la pobreza y la exclusión social (Warren, Thompson y Saegert, 2001), que insistan, desde los distintos ámbitos de gobierno, en la elaboración de políticas públicas para fomentar la cooperación, el soporte mútuo, la creación de redes, la confianza, la reciprocidad, el civismo y el bienestar colectivo (Putnam, 2000, p. 186). Todo esto como forma de seguro contra la pobreza y, a la vez, como herramienta para fortalecer la democracia, mejorar el componente institucional y promover el desarrollo (Valencia, Aguirre y Flórez, 2008).

En momentos como el actual, en los que se está trabajando en la elaboración y ajuste de planes de desarrollo de gobernaciones y alcandías, es oportuno incorporar en los programas de gobierno proyectos e iniciativas para fomentar la construcción y expansión de capital social, programas que promuevan la confianza y la solidaridad entre la población colombiana. Bajo este contexto, consignas de equidad y desarrollo social cobran la mayor relevancia, máxime cuando existe un llamado generalizado a la empatía y a construir con los otros la nueva normalidad.

El capital social también existe entre personas con cuotas desiguales de poder. El capital social de unión puede facilitar el acceso a recursos en la localidad y probablemente de una manera más rápida, para responder a momentos de emergencia y crisis, siempre y cuando la crisis no afecte también a los otros miembros de estas redes locales (Portes, 1999). Probablemente, es el tipo de capital social que más sentido de pertenencia ofrece. Aunque hay que advertir que el fomento del capital social puede tener su lado oscuro, al exigir del ciudadano más compromisos, más controles sociales y más demandas de reciprocidad, es decir, cuando se incorpora en relaciones de poder diferencial dentro de la misma comunidad puede incluir formas de intercambio desigual y de dominación cotidiana.

Lo anterior es relevante pues en países con alto riesgo de corrupción e instituciones políticas extractivistas, como las que aún persisten en Colombia (Acemoglu y Robinson, 2012), el mal uso del capital social es una amenaza real que opera en condiciones normales a toda marcha y que en un estado de emergencia, en donde existen situaciones que justifican contrataciones más expeditas, la contratación de ayudas, particularmente alimentarias, ofrecen 
condiciones favorables para que las redes de crimen organizadas en torno a la ejecución de los recursos estatales busquen sacar provecho de la situación.

No obstante, la creación de capital social es simple. Las acciones colectivas se facilitan cuando mejoran las relaciones entre las personas. En principio, el capital social se acrecienta en la medida que se usa. En general, cuando se pide ayuda a otros y se obtiene respuesta positiva se incrementa la confianza y con ello el capital social. En este sentido, ayuda el principio de reciprocidad generalizada — el cual se sustenta en la creencia de que un beneficio concedido hoy será devuelto en el futuro- que limita las conductas oportunistas y lleva a un incremento de la confianza por parte de quienes participan de ese tipo relaciones, a medida que las expectativas puestas en los otros son concretadas.

Algunas recomendaciones concretas para las administraciones públicas en torno a la construcción de capital social son: a) desarrollar políticas públicas para la creación de redes que permitan fomentar entre los ciudadanos la confianza y la participación; b) la focalización de las ayudas en sectores vulnerables con el fin priorizar adecuadamente las ayudas entre quienes más lo necesitan, desarrollando a la vez capital social que permita a las comunidades encontrar soluciones autogestionadas; asimismo, c) diseñar programas de apoyo que vallan más allá de lo financiero o alimentario, procurando generar capacidades en los sectores intervenidos; y d) cuidar los recursos provenientes de la solidaridad de manera especial, garantizando que se conserve la confianza de los ciudadanos en las instituciones.

Por último, una advertencia, el capital social nunca opera como único capital. El activo capital social no reemplaza a los activos económicos, laborales, ni el papel de las políticas públicas y del mercado. Se requieren recursos naturales, físicos, humanos y financieros para salir adelante (Banco Mundial, 2001). Se precisan también nichos de oportunidades: mercado, oportunidades de empleo, baja segregación social y baja discriminación. Los nichos de oportunidades están influidos por la existencia de capital social, sobre todo de los tipos puente y escalera, pero son más que este capital (Durston, 2003).

En conclusión, el capital social permite a las personas ampliar las oportunidades y disminuir la vulnerabilidad. Es un recurso que puede ser utilizado por las personas para afrontar situaciones de crisis. Estos contactos 
también ayudan a que los individuos puedan protegerse de la pobreza y el hambre. Es la dificultad de acceso a recursos, bienes y servicios, y el potencial que tiene el capital social para aumentar las oportunidades y capacidades para que los invididuos desarrollen una vida digna los que hacen al capital social, en la coyuntura actual, especialmente importante para las personas en situación de pobreza o riesgo de caer en ella.

\section{Germán Darío Valencia Agudelo (Colombia)* Antonio Hoyos Chaverra (Colombia)**}

\section{Referencias bibliográficas}

1. Acemoglu, Daron y Robinson, James. (2012). Por qué fracasan los países. Los orígenes del poder, la prosperidad y la pobreza. Bogotá, D. C.: Deusto.

2. Banco Mundial. (2001). Informe sobre el Desarrollo Mundial 2000/2001. Lucha contra la pobreza. Panorama general. Washington, D. C.: Banco Mundial.

3. Departamento Administrativo Nacional de Estadística (DANE). (2019, mayo 3). Boletín técnico Pobreza multidimensional en Colombia. Año 2018. Recuperado de https://www.dane.gov.co/files/investigaciones/condiciones_vida/pobreza/2018/ bt_pobreza_multidimensional_18.pdf

4. Departamento Administrativo Nacional de Estadística (DANE). (2020). Mercado Laboral. Principales resultados. Recuperado de https://www.dane.gov.co/ files/investigaciones/boletines/ech/ech/pres_web_empleo_rueda_prensa_abr_20.pdf

5. Durston, John. (2003). Capital social: parte del problema, parte de lasolución, su papel en la persistencia y en la superación de la pobreza en América Latina y el Caribe. En: Atria, Raúl; Siles, Marcelo; Arriagada, Irma; Robison, Lindon J. y Whiteford, Scott (comps.). Capital social y reducción de la pobreza en América Latina y el Caribe: en busca de un nuevo paradigma (pp. 147-202). Santiago: Cepal, MSU.

\footnotetext{
* Director revista Estudios Políticos. Economista. Especialista en Gerencia Social. Magíster en Ciencia Política. Doctor en Estudios Políticos. Grupo Hegemonía, guerras y conflictos, Instituto de Estudios Políticos, Universidad de Antioquia UdeA. Calle 70 No. 52-21, Medellín, Colombia. Correo electrónico: german.valencia@udea.edu.co - Orcid: 0000-0002-6412-6986 - Google Scholar https:// scholar.google.es/citations?user=7Sm8z3MAAAAJ\&hl=es

** Ingeniero Industrial. Magíster en Ingeniería de Sistemas. Estudiante de maestría en Economía Aplicada. Profesor Departamento de Ingeniería Industrial, Universidad de Antioquia UdeA. Calle 70 No.52-21, Medellín, Colombia. Correo electrónico: jahoyosch@udea.edu.co
}

Cómo citar este artículo: Valencia Agudelo, Germán Darío y Hoyos Chaverra, Antonio. (2020). Editorial. Contribución del capital social a los desafíos sociales y económicos que plantea el Covid-19. Estudios Politicos (Universidad de Antioquia), 58, pp. 9-15. DOI: 10.17533/udea.espo.n58a01 
6. James, Sherman A.; Schultz, Amy \& van Olphen, Juliana. (2001). Social Capital, Poverty, and Community Health: An Exploration of Linkages. In: Saegert, Susan \& Thompson, J. Phillip \& Warren, Mark R. (eds.). Social Capital and Poor Communities (pp. 165-188). New York: Russell Sage Foundation.

7. Pitas, Nicholas \& Ehmer, Colin. (2020). Social Capital in the Response to COVID-19. American Journal of Health Promotion, 1-3. https://doi. org/10.1177/0890117120924531

8. Portes, Alejandro. (1999). Capital Social: Sus orígenes y aplicaciones en la sociología moderna. En: Carpio, Jorge. y Novacovsky, Irene. (comps.). De igual a igual. El desafío del Estado ante los nuevos problemas sociales (pp. 243-266). Buenos Aires: FCE.

9. Putnam, Robert. (1993). Making Democracy Work: Civic Traditions in Modern Italy. Princeton: Princeton University. https://doi.org/10.2307/j.ctt7s8r7

10. Putnam, Robert. (2000). Bowling Alone: The Collapse and Revival of American Community. New York: Simon \& Schuster.

11. Rajkumar, Ravi. (2020). COVID-19 and mental health: A review of the existing literature. Asian Journal of Psychiatry, 52. https://doi.org/10.1016/j.ajp.2020.102066

12. Restrepo Restrepo, Piedad Patricia y Valencia Agudelo, Germán Darío. (2009). El capital social en Medellín: medición, determinantes y diseño de políticas públicas para su fomento. Medellín: Alcaldía de Medellín, Universidad de Antioquia.

13. Valencia Agudelo, Germán Darío; Aguirre Pulgarín, Mary Luz y Flórez Acosta, Jorge Hernán. (2008). Capital social, desarrollo y políticas públicas en Medellín, 20042007. Estudios Políticos, 32, pp. 53-83. Recuperado de https://revistas.udea.edu.co/ index.php/estudiospoliticos/article/view/1248

14. Warren, Mark \& Thompson, J. Phillip and Saegert, Susan. (2001). The Role of Social Capital in Combating Poverty. In: Saegert, Susan \& Thompson, J. Phillip \& Warren, Mark R. (eds.). Social Capital and Poor Communities (pp. 1-28). New York: Russell Sage Foundation. 